\title{
ESTUDO HIDROSSEDIMENTOLÓGICO E DA QUALIDADE DA ÁGUA NA FASE DE CONSTRUÇÃO DA PCH SACRE 2
}

\author{
André de Souza Faria \\ MBA em Perícia, Auditoria e Gestão Ambiental \\ Gustavo Aveiro Lins \\ CEDERJ/SEE-RJ/CEDAE
}

Roberto Ricardo Rachid Saab Barbosa Cunha

Observatório Urbano/OUERJ/UN-Habitat

\author{
Manoel Gonçalves Rodrigues \\ Observatório Urbano/UERJ/UN-Habitat \\ Josimar Ribeiro de Almeida \\ Observatório Urbano/UERJ/UN-Habitat
}

\section{RESUMO}

Qualquer ação na bacia de um rio, a qual altere suas características de fluxo, profundidade de canal e quantidade de material sólido em suspensão, entre outros parâmetros, tem uma correlação simples com a alteração de sua morfologia e conseqüente influencia na biodiversidade do sistema. Os estudos do inventário hidrelétrico de parte do rio Sacre (MT), apresentados pela Brasil Central Engenharia, foram aprovados pela Aneel. Ao longo do trecho avaliado, foram identificados cinco aproveitamentos, com uma potência global de 133,8 MW. A aprovação, no entanto, não assegura à empresa a obtenção ou autorização para o aproveitamento hidráulico. Um dos maiores problemas dos projetos hidrelétricos, assim como de outras fontes de energia, é a obtenção das licenças ambientais. Ao contrário das termoelétricas, que são construídas em grandes centros urbanos, as hidrelétricas são instaladas em áreas afastadas, mas, em alguns casos, de preservação ambiental o que inviabiliza a construção da usina. Caso do projeto de Belo Monte, no Rio Xingu, no Pará, que não consegue sair do papel por pressões de ambientalistas nacionais e estrangeiros, que temem prejuízos à natureza. A construção da PCH Sacre 2 (autorizada pela Resolução n ${ }^{\circ} 189$ de 04.05.2004 da ANEEL) que visa o aproveitamento do desnível do terreno não utilizando de reservatório propõe oferecer menores alterações que possam prejudicar o curso d'água. Para avaliação de tal fato torna-se necessário o monitoramento Hidrossedimentológico e da qualidade da água do Rio Sacre no entorno de tal empreendimento. Tal monitoramento é integrante de um Plano de Controle Ambiental exigido pelo órgão ambiental periodicamente para que haja um controle das alterações causadas ao meio.

Palavras-chave: PCH, Monitoramento, Hidrossedimentologia

\section{ABSTRACT}

Any action in the basin of the river, which alters their flow characteristics, channel depth and amount of solid material in suspension, among other parameters, have the simple correlation with the alteration of morphology and consequent it influences in the biodiversity of the system. The studies of the hydroelectric inventory of part of the Sacre river (MT), presented by Brasil 
Central Engineering, they were approved for Aneel. Along the appraised passage, they were identified five uses, with a global potency of $133,8 \mathrm{MW}$. The approval, however, it doesn't assure to the company the obtaining or authorization for the hydraulic use. One of the largest problems of the hydroelectric projects, as well as of other sources of energy, it is the obtaining of the environmental licenses. Unlike the thermoelectrical ones, that are built in great urban centers, the hydroelectric power stations are installed in moved away areas, but, in some cases, of environmental preservation - what makes unfeasible the construction of the plant. In case of Beautiful Monte's project, in Xingu river, in Pará, that doesn't get to leave the paper for national and foreign environmentalists' pressures, that fear damages to the nature. The construction of PCH Sacre 2 (authorized for the Resolution $n^{\circ} 189$ of 04.05 .2004 of ANEEL) that seeks the use of the unevenness of the land not using of reservoir intends to offer smaller alterations than they can harm the course of it longs for. For evaluation of such fact becomes necessary the monitoring Hidrossedimentológico and of the quality of Sacre river water spill it of such enterprise location. Such monitoring is integral of a Plan of Environmental Control demanded by the environmental organ periodically so that there is a control of the alterations caused to the middle.

Key-words: $\mathrm{PCH}$, Monitoring, Hidrossedimentologia.

\section{INTRODUÇÃO}

O presente trabalho apresenta o estudo Hidrossedimentológico e da Qualidade da Água no rio Sacre, onde está sendo construída a PCH Sacre 2, autorizada pela Resolução n 189 de 04.05.2004 da ANEEL,

Este empreendimento localiza-se na margem direita do rio Sacre com aproveitamento hidráulico da cachoeira Salto Belo, que é sub-bacia do rio Juruena e pertence à bacia hidrográfica do rio Amazonas com geração prevista de $30 \mathrm{MW}$ de potencia instalada, situada sob as coordenadas geográficas $13^{\circ} 01^{\prime} 38.8^{\prime \prime}$ e $58^{\circ} 11^{\prime} 20.6^{\prime \prime} \mathrm{W}$. Aproveitamento hidráulico este que operará a fio d'água dispensando barramento do curso d'água para regularização da vazão líquida, pois estudos hidrológicos realizados para autorização do empreendimento relatam que o Rio Sacre Possui uma vazão firme.

Esta caracterização do comportamento da hidrossedimentologia e de qualidade de água da PCH Sacre 2, refere-se a fase de construção do empreendimento. Este diagnóstico de monitoramento foi programado para seis campanhas trimestrais, a montante e a jusante do empreendimento. O levantamento busca avaliar as alterações ambientais que ocorrem nas águas do rio Sacre nas proximidades desta hidrelétrica em construção, através das variáveis físicos e organolépticos, físico-químicas, biológicos e hidrossedimentométricos.

O objetivo geral deste trabalho é realizar um estudo Hidrossedimentológico e da Qualidade da água na área de construção da Pequena Central Hidrelétrica 
(PCH) Sacre 2. E como objetivos específicos, podemos citar a avaliação das alterações ambientais que ocorrem nas águas do rio Sacre nas proximidades desta hidrelétrica em construção, através das variáveis físicas e organolépticas, físico-químicas, biológicas e hidrossedimentológicas.

\section{RESULTADOS E DISCUSSÃO}

\section{Sobre a Qualidade da Água}

A partir dos dados das variáveis físicos e organolépticos, físico-químicas, biológicas e pelo Índice de Qualidade da Água apresenta-se o desenvolvimento deste estudo sobre a qualidade da água no rio Sacre.

- Transparência

A natureza da água no rio Sacre nestas seções em estudo, apresentou transparência total, tanto à montante e à jusante do reservatório.

\section{- Temperatura}

As medições de temperatura do ar e água foram realizadas no momento das coletas de água, os valores encontrados para a temperatura na água foram muito próximos, tanto na estação de montante como na de jusante, conforme se apresenta na figura 1 .

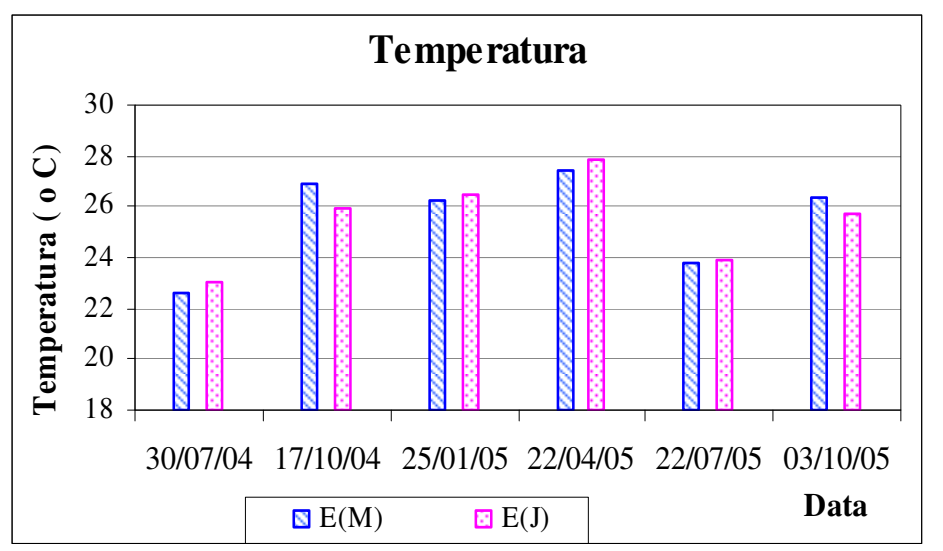

Figura1 - Variação dos valores de temperatura da água nas estações de amostragem à montante e jusante da PCH Sacre 2.

- $\mathrm{pH}$ 
Os valores de $\mathrm{pH}$ nestas campanhas foram próximos tanto a montante como a jusante da $\mathrm{PCH}$ Sacre 2. em três das campanhas realizadas os valores encontraram-se abaixo dos limites permitidos pela Resolução CONAMA $n^{\circ}$ 357/05 para rios de Classe 2, conforme ilustrado na figura 2.

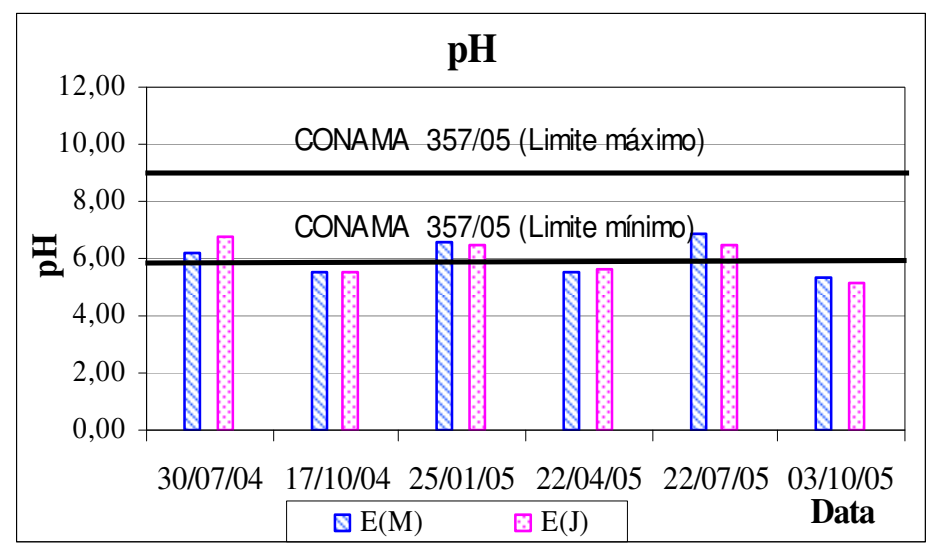

Figura 2 - Variação dos valores de pH nas Estações de amostragem à montante e jusante da PCH Sacre 2.

\section{- Cor}

A cor observada nos dois pontos amostrados encontrou-se superior na campanha de outubro/2005. Conforme a figura 3 verifica-se que os valores apresentados de cor encontram-se bem abaixo do limite de $75 \mathrm{mg} \mathrm{Pt/L}$ estabelecido pela Resolução CONAMA 357/05, para rios de Classe 2.

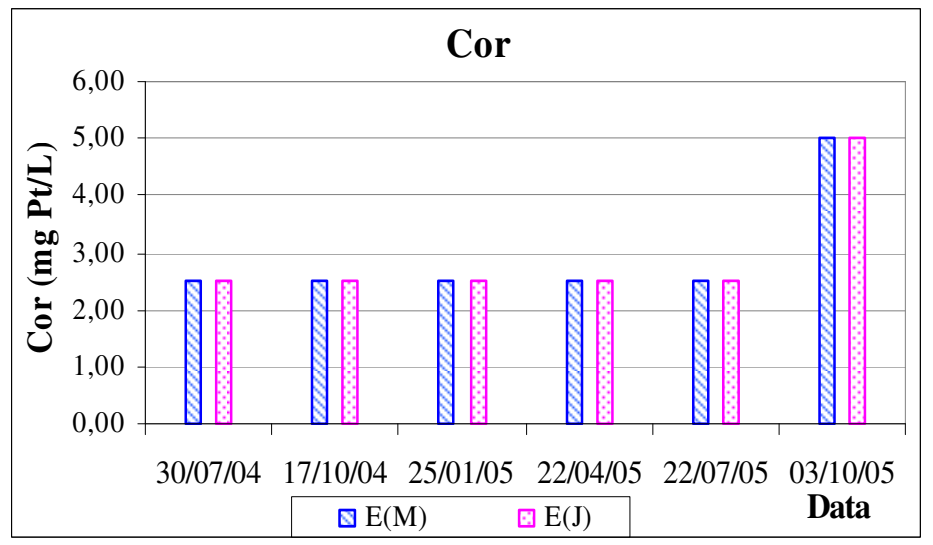

Figura 3 - Variação dos valores de cor nas Estações de amostragem à montante e à jusante da $\mathrm{PCH}$ Sacre 2.

\section{- Turbidez}


Os valores obtidos foram próximos na estação à montante e à jusante da $\mathrm{PCH}$ Sacre 2, exceto nas campanhas de julho/2004, janeiro/2005 e abril/2005;período o qual houve escavações mais intensas.Porém todos valores de turbidez obtidos estão bem abaixo dos limites estabelecidos pela Resolução CONAMA no $\div$ 357/05 para o corpo d'água que é de 100 NTU. Estes valores podem ser visualizados na figura 4 .

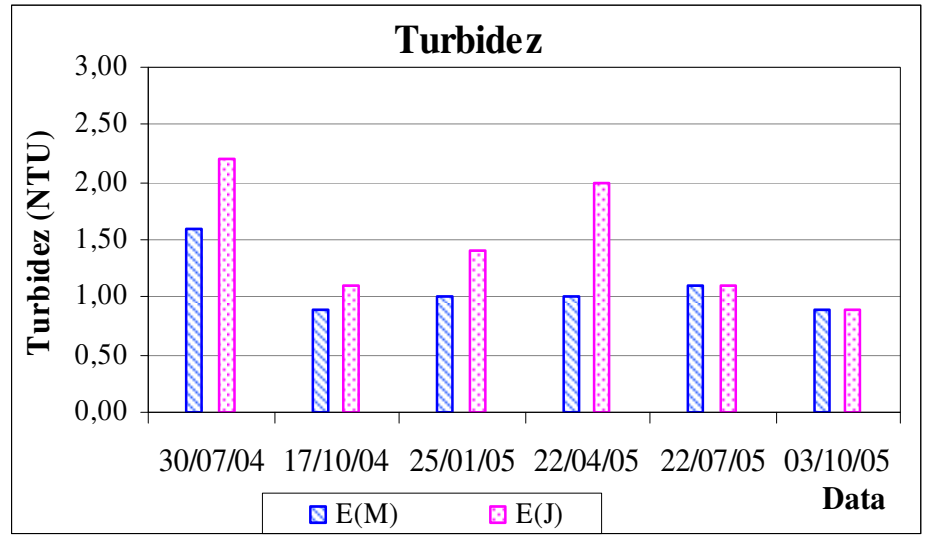

Figura 4 - Variação dos valores de turbidez nas Estações de amostragem à montante e à jusante da PCH Sacre 2.

\section{- Alcalinidade Total}

Os valores de Alcalinidade Total permaneceram próximos e se elevaram levando-se em consideração às campanhas anteriores, como ilustra a figura 5 .

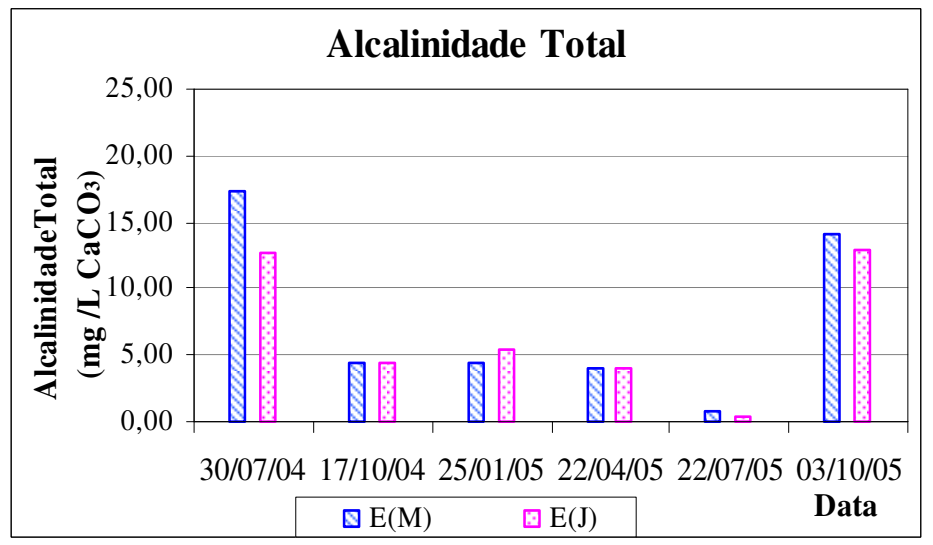

Figura 5 - Variação dos valores de alcalinidade nas Estações de amostragem à montante e à jusante da $\mathrm{PCH}$ Sacre 2.

\section{- Dureza Total}

$\mathrm{Na}$ maioria das campanhas não foi detectada dureza total nas amostras 
coletadas tanto na estação de montante como de jusante, respectivamente, exceto na campanha de julho/2004 que apresenta pequenos valores. (figura 6).

Valores abaixo de $50 \mathrm{mg} / \mathrm{L}$ é considerada uma água mole. A água do rio Sacre tem uma tendência a ter uma dureza igual ou menor que a alcalinidade, que corresponderia a possuir somente dureza de carbonatos e o excesso de alcalinidade corresponde a carbonatos e bicarbonatos de $\mathrm{Na}$ e $\mathrm{K}$ (GAGLIANOME \& BASTOS, 1988 in MACEDO, 2001).

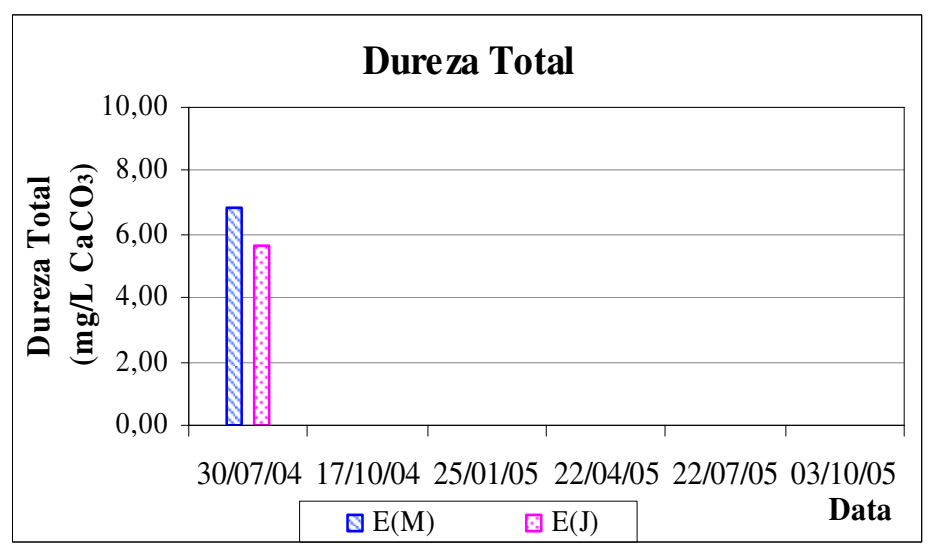

Figura 6 - Variação dos valores de dureza total nas Estações de amostragem à montante e à jusante da PCH Sacre 2.

\section{- Condutividade Elétrica}

Os dados de condutividade obtidos com as amostras apresentam uma aparente variação tanto a montante como à jusante do empreendimento. Estes valores estão apresentados na figura 7.

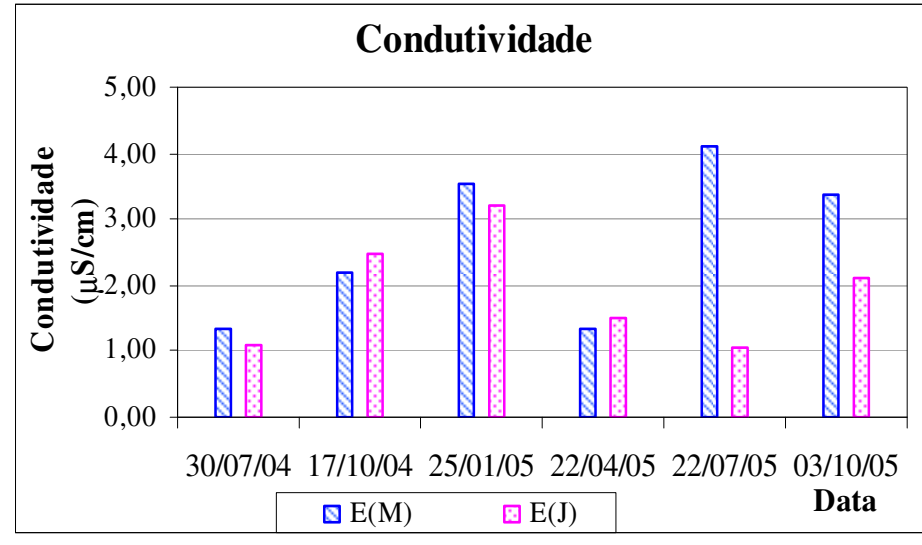

Figura 7 - Variação dos valores de condutividade nas Estações de amostragem à montante e à jusante da PCH Sacre 2. 


\section{- Oxigênio Dissolvido}

Os valores obtidos de Oxigênio Dissolvido encontram-se estáveis. Os valores se mantiveram constantes tanto a montante da $\mathrm{PCH}$ como a jusante da $\mathrm{PCH}$, como ilustra na figura 8 .

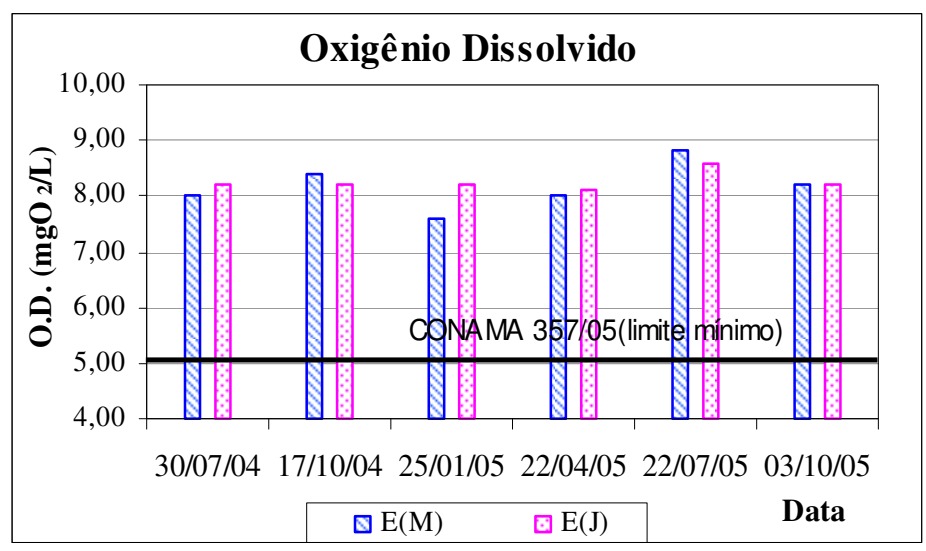

Figura 8 - Variação dos valores de Oxigênio Dissolvido nas estações de amostragem, à montante e jusante da PCH Sacre 2.

\section{- Demanda Bioquímica de Oxigênio - DBO}

Os valores de DBO obtidos no decorrer das campanhas foram inferiores a 1,0 $\mathrm{mg} / \mathrm{L}$, portanto, bem abaixo do limite máximo estabelecido pela Resolução CONAMA 357/05 que é de 5,0 mg/L. Tais valores indicaram um baixo consumo de oxigênio nos processos biológicos de decomposição da matéria orgânica e respiração pelos microrganismos vivos do sistema na campanha. A figura 9 ilustra os valores constantes de DBO durante as campanhas de monitoramento.

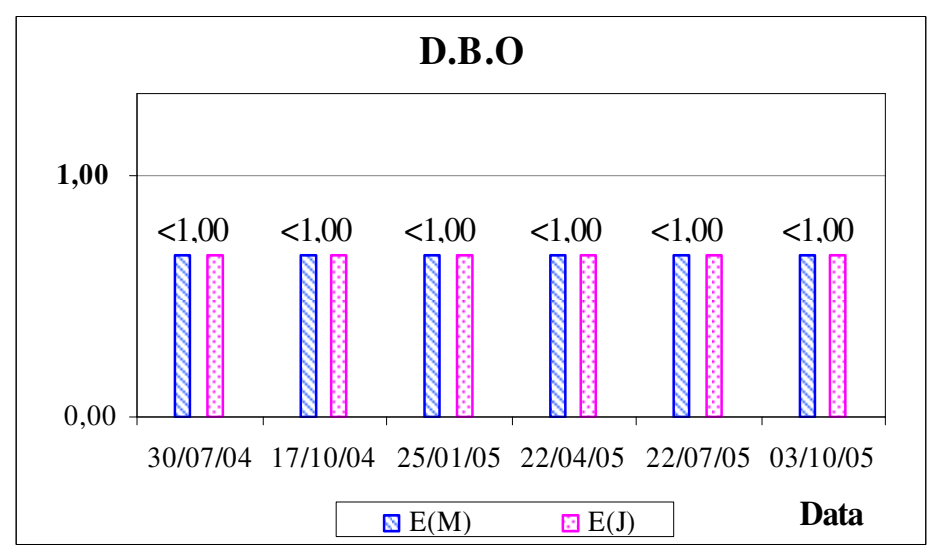

Figura 9 - Variação dos valores de DBO nas Estações de amostragem à montante e à jusante da PCH Sacre 2 


\section{- Demanda Química de Oxigênio - DQO}

O maior valor registrado da variável DQO ocorreu na estação à montante da $\mathrm{PCH}$ Sacre 2, com 6,38 mg/L(campanha de outubro/2005) e o menor valor observou-se na estação de jusante, com 0,73 mg/L(campanha de julho/2004). As variações dos valores de DQO durante as campanhas de monitoramento estão apresentadas na figura 10.

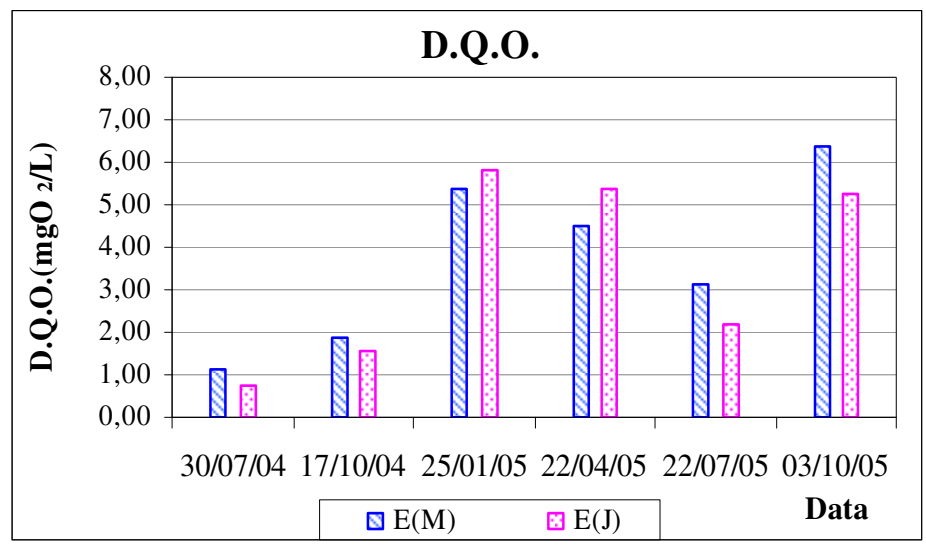

Figura 10 - Variação dos valores de DQO nas Estações de amostragem à montante e à jusante da $\mathrm{PCH}$ Sacre 2.

\section{- Nitrogênio Total Kjeldahl - NTK}

Observa-se na campanha de outubro/2005, que os valores de nitrogênio total tiveram relativo aumento nos valores, sendo de $0,250 \mathrm{mg} / \mathrm{L}$ a montante e de $<0,20 \mathrm{mg} / \mathrm{L}$ a jusante da $\mathrm{PCH}$ Sacre 2. A figura 11 ilustra as variações dos valores de nitrogênio total nos pontos amostrados durante as cinco campanhas.

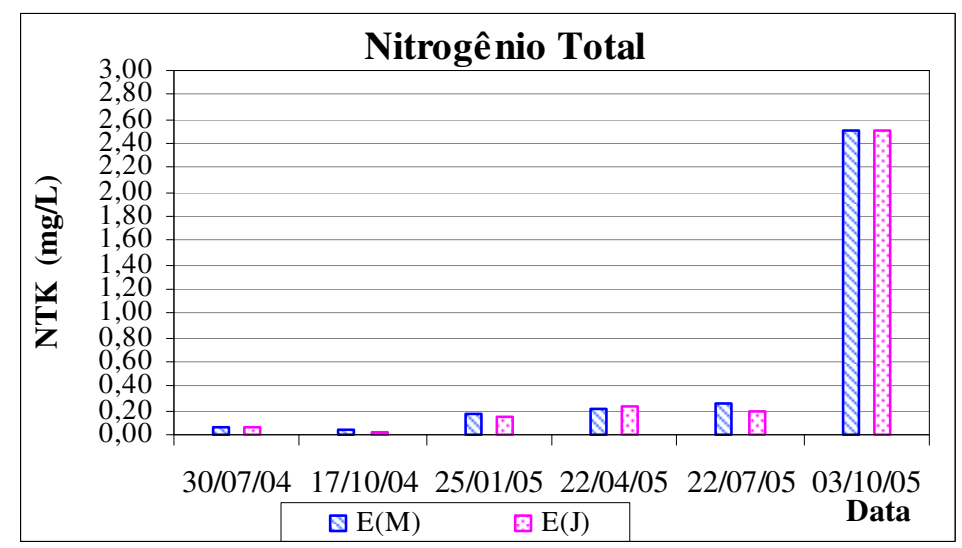

Figura 11 - Valores de NTK nas Estações de amostragem à montante e à 
jusante da PCH Sacre 2

\section{- Fósforo Total}

Os valores de Fósforo Total permaneceram com resultados constantes a montante e a jusante da $\mathrm{PCH}$ Sacre 2.com exceção das campanhas de outubro/2004 e julho/2005.A figura 12 ilustra a variação dos valores encontrados nas campanhas de monitoramento, confirmando que os valores encontram-se bem abaixo do limite máximo estabelecido pela Resolução CONAMA n³57/05, que é de $0,030 \mathrm{mg} / \mathrm{L}$.

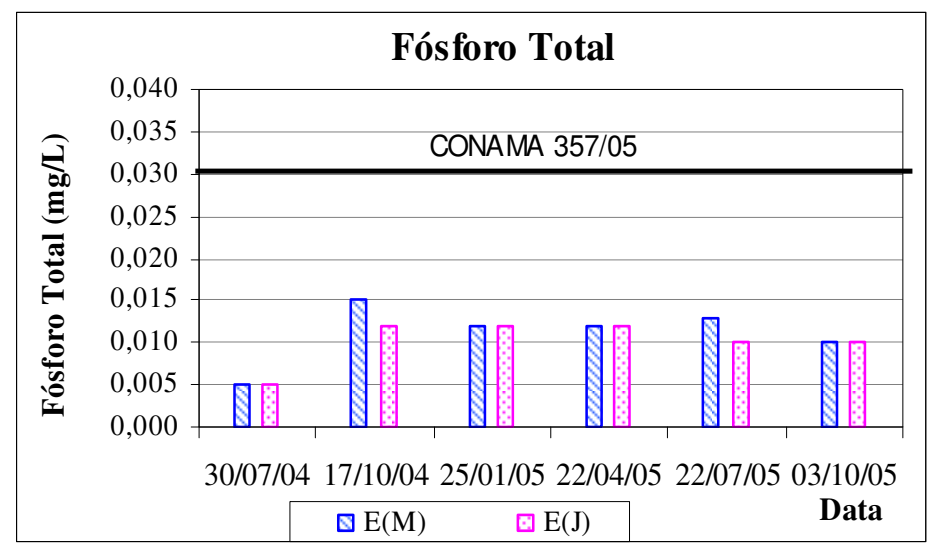

Figura 12 - Valores de fósforo total nas Estações à montante e à jusante da $\mathrm{PCH}$ Sacre 2.

\section{Sólidos Totais - ST}

Os resultados obtidos de sólidos totais nestas campanhas tiveram grande variação, o menor valor foi de $1,00 \mathrm{mg} / \mathrm{L}$ (campanha de outubro/2004 e julho/2005) tanto a montante como à jusante da PCH Sacre 2 e o maior resultado foi $41,00 \mathrm{mg} / \mathrm{L}$ (campanha de julho/2004 e abril/2005) . A figura 13 mostra as variações das concentrações de sólidos totais durante as cinco campanhas realizadas, tal discrepância entre os valores de sólidos totais pode estar relacionada às atividades antrópicas no período de construção da $\mathrm{PCH}$. 


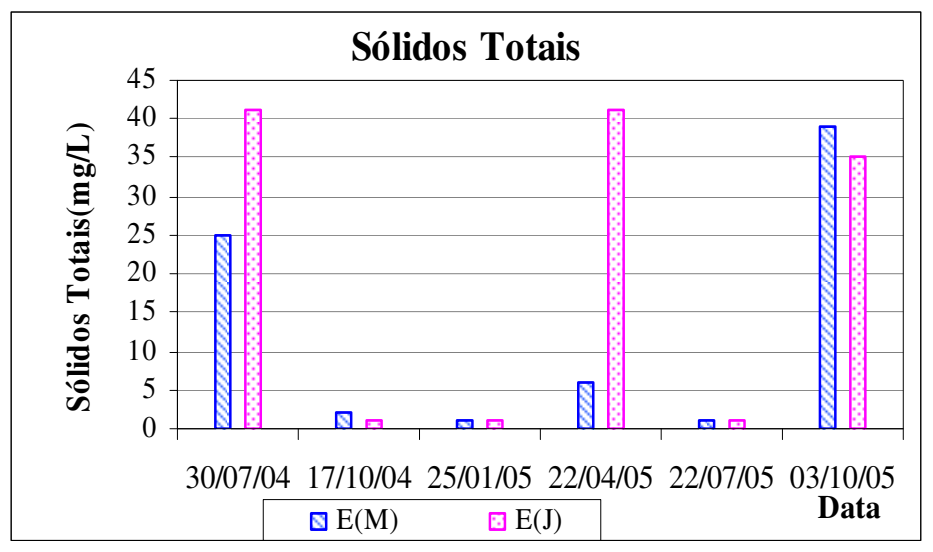

Figura 13 - Variação dos valores de sólidos totais nas Estações à montante e jusante da PCH Sacre 2.

\section{- Sólidos Dissolvidos Totais - SDT}

Os valores observados mostram valores próximos entre os pontos de montante e de jusante exceto nas campanhas de julho/2004 e abril/2005, onde provavelmente tal variação se deve ao período de escavações na obra. 0 maior valor à montante da PCH Sacre $2 \mathrm{com} 0,80 \mathrm{mg} / \mathrm{L}$ e no ponto à jusante foi obtido o valor de 0,20 mg/L. Tais variações podem ser observadas na figura 14 .

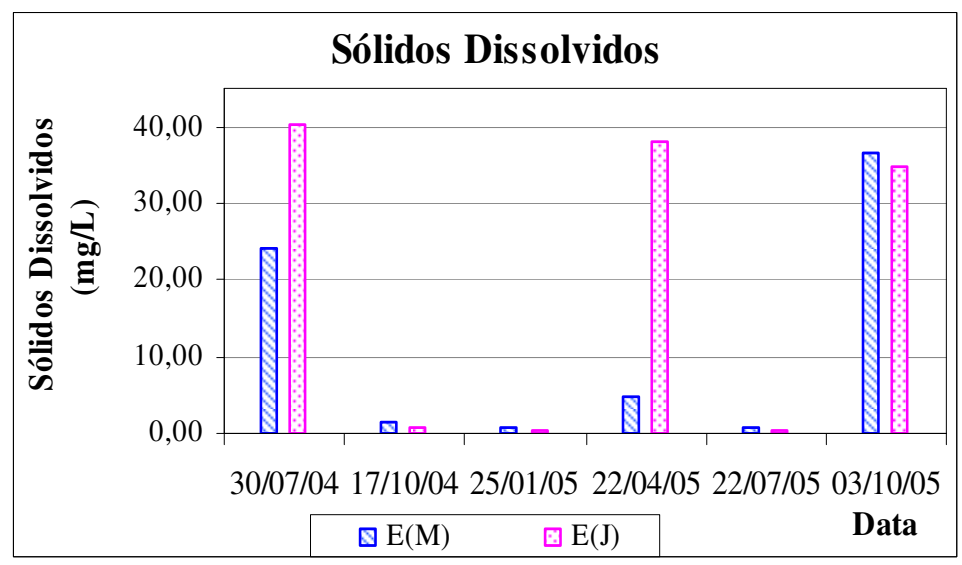

Figura 14 - Variação dos valores de sólidos dissolvidos totais nas Estações à montante e à jusante da PCH Sacre 2.

\section{Sólidos Suspensos Totais - SST}

Os teores de sólidos suspensos podem ser visualizados na figura 15 onde se observa na campanha de outubro/2005 um maior valor à montante do empreendimento e o menor valor foi na estação de jusante, tal fato possivelmente deve-se a sedimentação dos mesmos no leito do rio, visto que a 
jusante tem-se uma baixa velocidade e maior profundidade.

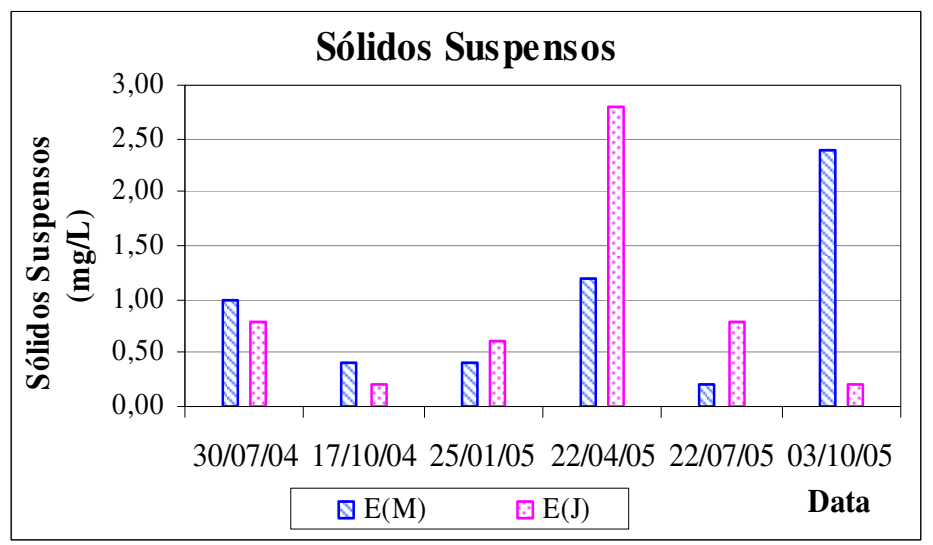

Figura 15 - Variação dos valores de sólidos suspensos totais nas Estações à montante e à jusante da $\mathrm{PCH}$ Sacre 2

\section{- Sólidos Sedimentáveis - Sol. Sed.}

Foram obtidos nestas campanhas de monitoramento, valores de sólidos sedimentáveis baixos em todos os pontos, tanto na estação à montante como na estação à jusante da PCH. Tais valores foram todos inferiores a $0,10 \mathrm{ml} / \mathrm{L}$. Pela Resolução 357/05 do CONAMA, a sua restrição é no artigo 34, em que a qualidade do corpo receptor não deve ultrapassar $1 \mathrm{ml} / \mathrm{L}$.

\section{Variáveis Biológicas}

As variáveis biológicas apresentadas neste estudo referem-se ao levantamento de coliformes totais e termotolerantes, clorofila total.

\section{Coliformes}

Os valores dos coliformes estão apresentados na tabela 1. As variações dos índices nas campanhas estão apresentadas nas figuras 16 e 17 para coliformes totais e termotolerantes, respectivamente.

Tabela 5 - Valores dos índices de Coliformes Totais e Termotolerantes nas estações de amostragem PCH Sacre 2 - outubro/2005 


\begin{tabular}{|c|c|c|c|c|}
\hline Data & $\mathrm{N}_{\text {Variáveis }}$ Estações & $\begin{array}{c}\text { Padrão } \\
\text { CONAMA 357/05 }\end{array}$ & $E(M)$ & $E(J)$ \\
\hline \multirow[b]{2}{*}{$30 / 07 / 2004$} & $\begin{array}{l}\text { Coliformes Totais } \\
\text { (N.M.P./100mL) }\end{array}$ & $5,0 \mathrm{E}+3$ & $3,60 \mathrm{E}+01$ & $1,50 \mathrm{E}+02$ \\
\hline & $\begin{array}{c}\text { Coliformes } \\
\text { Termotolerantes } \\
\text { (N.M.P./100mL) }\end{array}$ & $1,0 \mathrm{E}+3$ & $3,60 \mathrm{E}+01$ & $9,10 \mathrm{E}+01$ \\
\hline \multirow[b]{2}{*}{$17 / 10 / 2004$} & $\begin{array}{l}\text { Coliformes Totais } \\
\text { (N.M.P./100mL) }\end{array}$ & & $1,50 \mathrm{E}+02$ & $4,50 \mathrm{E}+02$ \\
\hline & $\begin{array}{c}\text { Coliformes } \\
\text { Termotolerantes } \\
\text { (N.M.P./100mL) }\end{array}$ & & $1,50 \mathrm{E}+02$ & $4,30 \mathrm{E}+02$ \\
\hline \multirow[b]{2}{*}{ 25/01/2005 } & $\begin{array}{l}\text { Coliformes Totais } \\
\text { (N.M.P./100mL) }\end{array}$ & & $2,10 \mathrm{E}+02$ & $2,10 \mathrm{E}+03$ \\
\hline & $\begin{array}{c}\text { Coliformes } \\
\text { Termotolerantes } \\
\text { (N.M.P./100mL) }\end{array}$ & & $1,50 \mathrm{E}+02$ & $9,30 \mathrm{E}+02$ \\
\hline \multirow[b]{2}{*}{$22 / 04 / 2005$} & $\begin{array}{l}\text { Coliformes Totais } \\
\text { (N.M.P./100mL) }\end{array}$ & & $1,50 \mathrm{E}+02$ & $1,50 \mathrm{E}+02$ \\
\hline & $\begin{array}{c}\text { Coliformes } \\
\text { Termotolerantes } \\
\text { (N.M.P./100mL) }\end{array}$ & & $1,20 \mathrm{E}+02$ & $1,50 \mathrm{E}+02$ \\
\hline \multirow[b]{2}{*}{ 22/07/2005 } & $\begin{array}{l}\text { Coliformes Totais } \\
\text { (N.M.P./100mL) }\end{array}$ & & $3,60 E+02$ & $9,10 \mathrm{E}+01$ \\
\hline & $\begin{array}{c}\text { Coliformes } \\
\text { Termotolerantes } \\
\text { (N.M.P./100mL) }\end{array}$ & & $3,60 \mathrm{E}+02$ & $3,60 \mathrm{E}+01$ \\
\hline \multirow[b]{2}{*}{ 03/10/2005 } & $\begin{array}{l}\text { Coliformes Totais } \\
\text { (N.M.P./100mL) }\end{array}$ & & $1,5 \mathrm{E}+02$ & $9,1 \mathrm{E}+01$ \\
\hline & $\begin{array}{c}\text { Coliformes } \\
\text { Termotolerantes } \\
\text { (N.M.P./100mL) }\end{array}$ & & $1,5 \mathrm{E}+02$ & $9,1 E+01$ \\
\hline
\end{tabular}

OBS.: N.M.P. - Número mais provável por 100mL. 
A Resolução CONAMA №. 357/05 estabelece valores máximos permitidos para rios de Classe 2 de 5000 e 1000 (NMP/100mL) para coliformes totais e termotolerantes, respectivamente. Durante este estudo, os índices de coliformes foram muito baixos nos dois pontos de amostragem, indicando água de boa qualidade quanto aos aspectos sanitários, conforme apresentado na tabela 1.

Os valores mais elevados registrados em janeiro/2005, em relação às outras campanhas foram provavelmente influenciados pelas precipitações do período em que as águas de chuvas carreiam grande quantidade de materiais alóctones da área de drenagem para o leito do rio. É provável que os valores mais elevados registrados em janeiro referem-se, em sua grande maioria, aos coliformes de origem de animais silvestres, uma vez que não há no entorno lançamentos de esgotos domésticos ou industriais.

Os índices destes bioindicadores de contaminação obtidos nas campanhas do corrente ano estão apresentados na tabela 5 . As variações destes índices podem ser visualizadas nas figuras 16 e 17 .

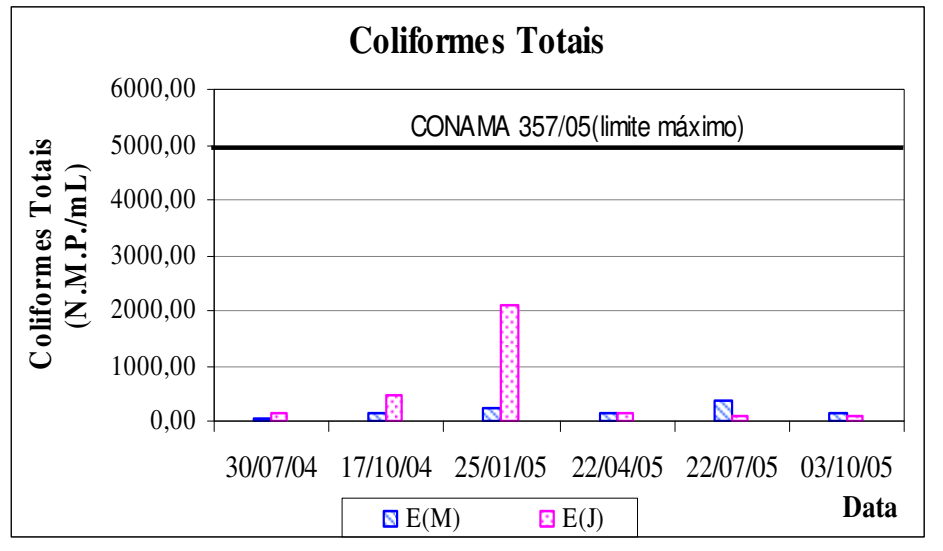

Figura 16 - Variação dos índices de coliformes totais nas estações de amostragem à montante e à jusante da PCH Sacre 2.

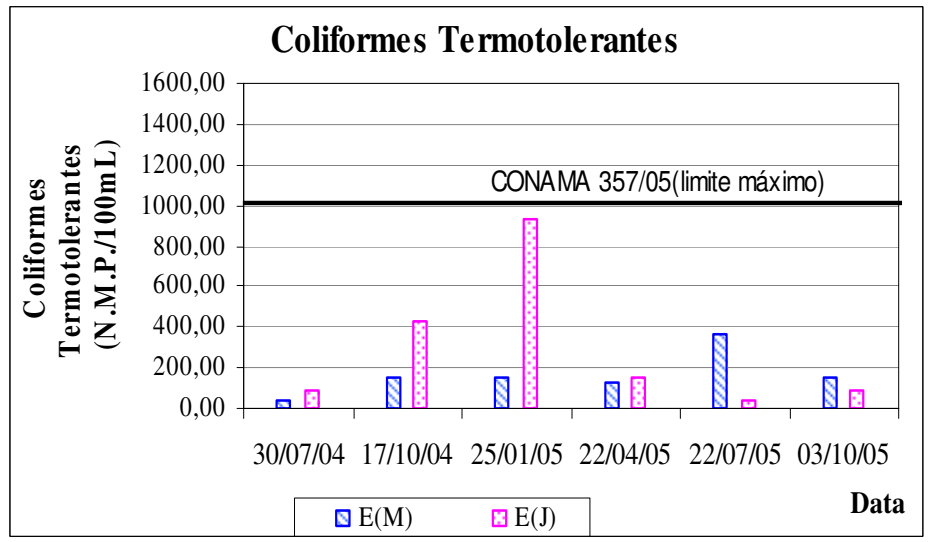


Figura 17 - Variação dos índices de coliformes termotolerantes nas estações de amostragem à montante e à jusante da PCH Sacre 2.

\section{Clorofila Total}

Segundo ESTEVES (1988) e ALLAN (1995), os principais fatores que afetam o crescimento da comunidade fitoplanctônica em rios são os mesmo que limitam o seu desenvolvimento em lagos, ou seja, os níveis de penetração da luz, temperatura e disponibilidade de nutrientes. Contudo, ALLAN (1995) cita que, de todos os fatores que influenciam o crescimento em ambientes lóticos, a velocidade de corrente e o regime de descarga são os mais importantes. No presente foram determinantes para os baixos valores de biomassa, medidos na forma de clorofila total, nos ambientes com característica lóticas.

Os valores das concentrações de clorofila foram muito baixos nos dois locais de amostragem do rio Sacre neste período de amostragem, refletindo a relativa pobreza de representantes da comunidade fitoplanctônica.

Segundo ESTEVES (1988) e ALLAN (1995), os principais fatores que afetam o crescimento da comunidade fitoplanctônica em rios são os mesmo que limitam o seu desenvolvimento em lagos, ou seja, os níveis de penetração da luz, temperatura e disponibilidade de nutrientes. Contudo, ALLAN (1995) cita que, de todos os fatores que influenciam o crescimento em ambientes lóticos, a velocidade de corrente e o regime de descarga são os mais importantes. No presente estudo, estes fatores foram determinantes para os baixos valores de biomassa, medidos na forma de clorofila total, nestes ambientes com característica lóticas.

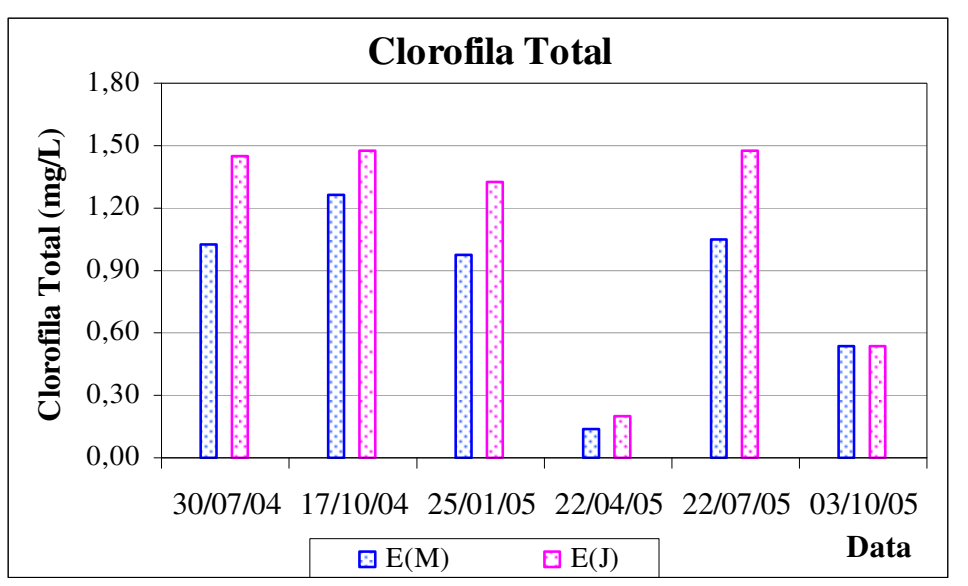

Figura 18 - Variação dos índices de clorofila total nas estações de amostragem 
à montante e jusante da PCH Sacre 2.

\section{Índice de Qualidade da Água - IQA}

Em complemento a análise da Qualidade da Água, o diagnóstico através do Índice de Qualidade da Água - IQA que foi a metodologia complementar utilizada para avaliar a qualidade da água da bacia hidrográfica nas proximidades do empreendimento, através das estações de coleta de amostras a montante e jusante do empreendimento estão apresentadas na tabela 2.

Tabela 2 - Valores de IQA e Classificação.

\begin{tabular}{c|c|c|c|c}
\hline Estações & \multicolumn{2}{|c|}{$\begin{array}{c}\mathrm{E}_{\mathrm{M}} \\
\text { Montante da } \\
\text { PCH Sacre 2 }\end{array}$} & \multicolumn{2}{c}{$\begin{array}{c}\text { EJ } \\
\text { Jusante da } \\
\text { PCH Sacre 2 }\end{array}$} \\
\hline \hline $30 / 07 / 2004$ & 81,7 & ótima & 81,7 & ótima \\
\hline $17 / 10 / 2004$ & 64,8 & boa & 70,1 & boa \\
\hline $25 / 01 / 2005$ & 69,9 & boa & 71,1 & boa \\
\hline $22 / 04 / 2005$ & 73,6 & boa & 72,7 & boa \\
\hline $22 / 07 / 2005$ & 76,2 & boa & 75,1 & boa \\
\hline $03 / 10 / 2005$ & 71,0 & boa & 72,2 & boa \\
\hline \hline
\end{tabular}

Pelos resultados encontrados nas campanhas sobre o IQA (figura 19), nas avaliações das 9 (nove) variáveis, as amostragens das águas da bacia do rio Sacre, nas estações $E_{M}$ e $E_{J}$ continuam enquadradas como de $B O A$ QUALIDADE.

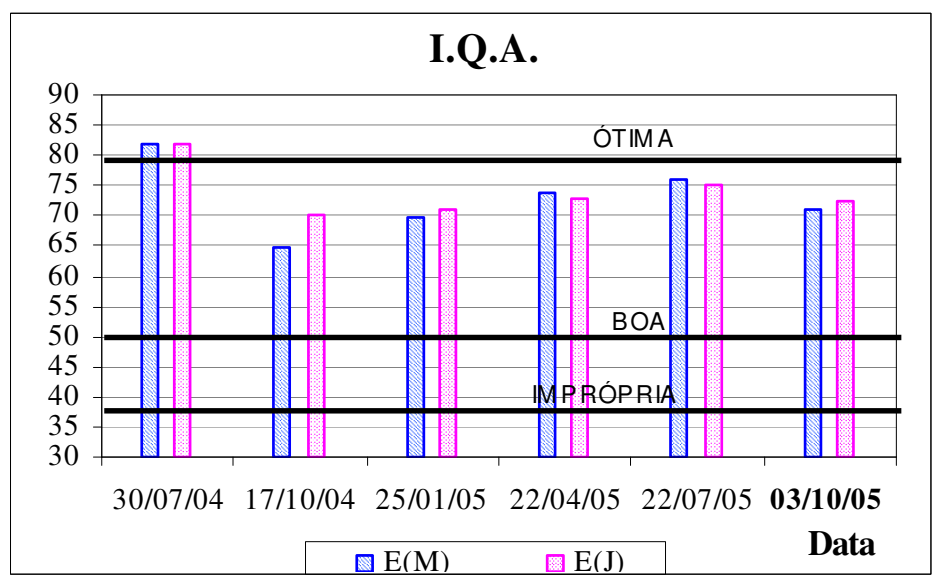

Figura 19 - Valores do IQA. 


\section{HIDROSSEDIMENTOLOGIA}

Os resultados mostram que ocorreu um aumento no transporte de sedimentos carreados em algumas campanhas, os quais também não são significativos, cuja alteração ocorreu tanto a montante como a jusante da $\mathrm{PCH}$.

Nesta etapa da construção as escavações estão adiantadas em termos de serviços de terraplenagem, em algumas etapas do cronograma físico em que se nota o maior movimento de terra, que pode implicar no escoamento para 0 leito do rio.

- Leitura do nível da água a partir do registrador fluviométrico digital

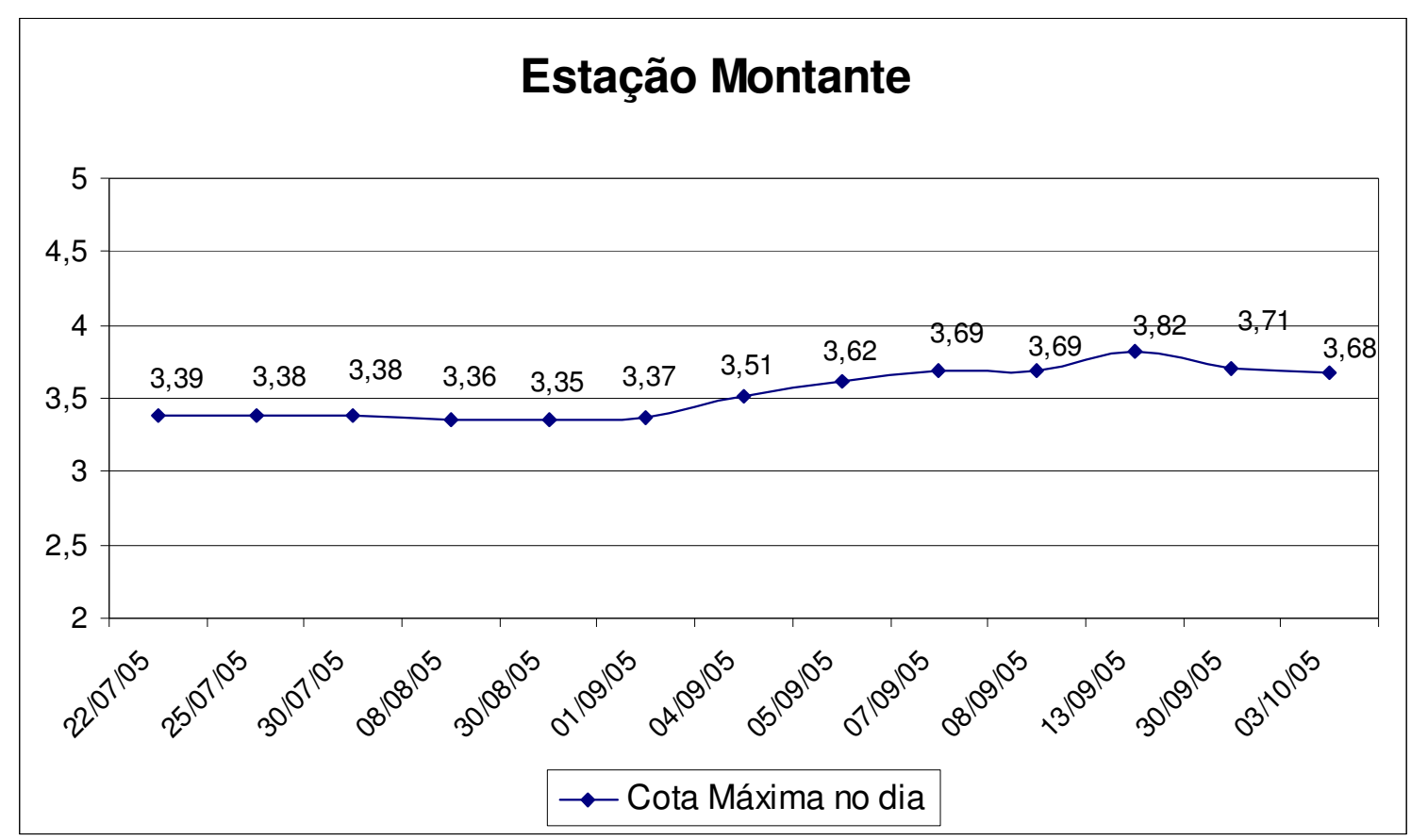

\section{NIMBUS do fabricante OTT.}

Figura 20 - Variação de nível de água na estação fluviométrica de montante $E_{(M)}$ leitura do Nimbus. 


\section{Estação Jusante}

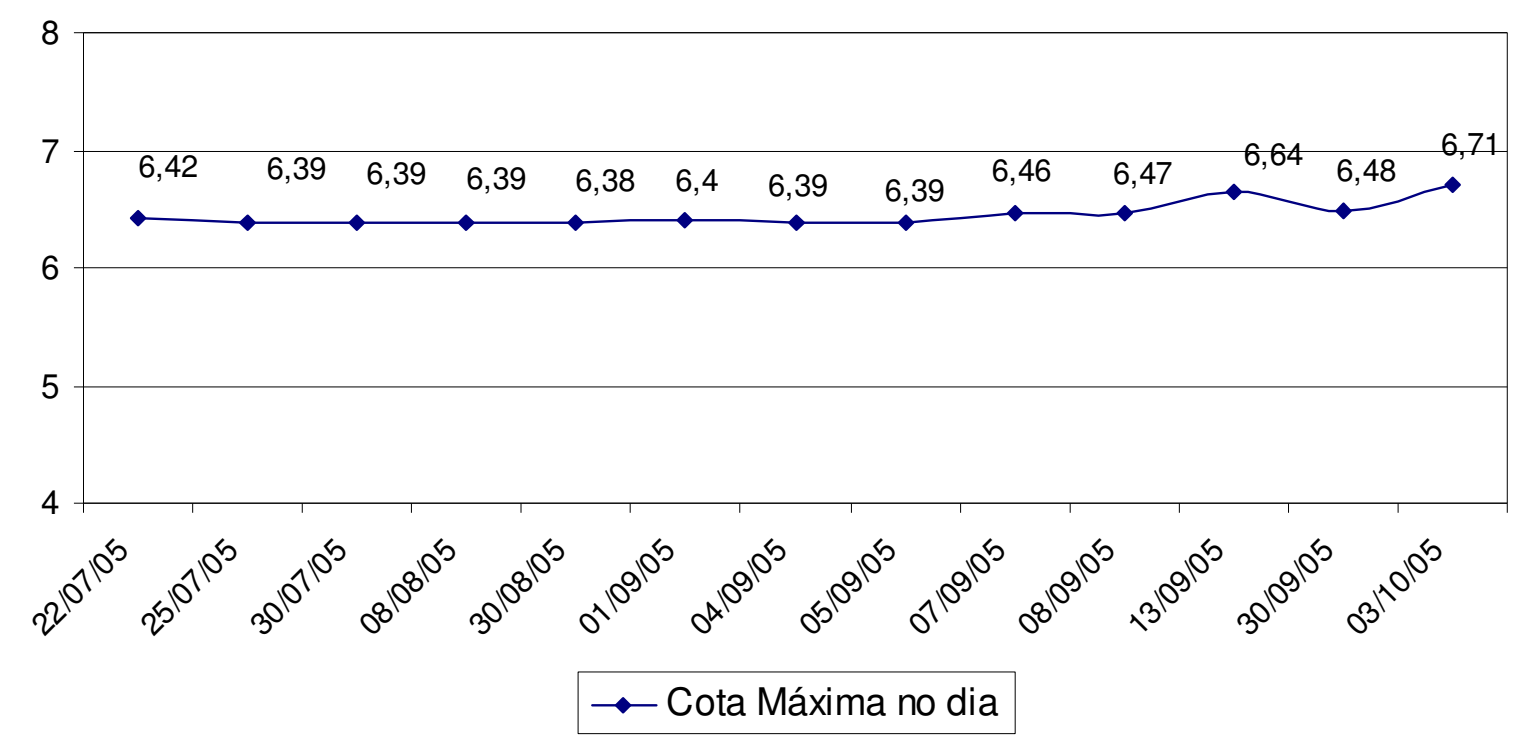

Figura 21 - Variação de nível de água na estação fluviométrica de jusante - $E_{(J)}$ leitura do Nimbus.

A avaliação hidrossedimentométrica mostra através das Tabelas 3 e 4, que as Vazões medidas no decorrer das campanhas, assim como o nível de águas nas seções fluviométricas, montante das seções fluviométricas em estudo.

Tabela 3 - Estação de montante $-\mathrm{E}_{(\mathrm{M})}$

\begin{tabular}{c|c|c|c|c}
\hline \hline Datas & $\begin{array}{c}\text { Régua } \\
\text { limnimétrica } \\
(\mathrm{m})\end{array}$ & Vazão $\left(\mathrm{m}^{3} / \mathrm{s}\right)$ & $\begin{array}{c}\text { Concentração } \\
\text { de sedimentos } \\
(\mathrm{ppm})\end{array}$ & $\begin{array}{c}\text { Descarga } \\
\text { sólida total } \\
\text { (ton/dia) }\end{array}$ \\
\hline 03/jul/2004 & 3,41 & 156,18 & 1,00 & 61,96 \\
\hline 16/out/2004 & 3,45 & 171,20 & 0,40 & 42,41 \\
\hline 25/jan/2005 & 3,62 & 214,16 & 0,40 & 61,48 \\
\hline 22/abr/2005 & 3,56 & 195,14 & 1,20 & 98,50 \\
\hline 22/jul/2005 & 3,39 & 154,52 & 0,20 & 23,20 \\
\hline 03/out/2005 & 3,69 & 147,44 & 2,40 & 86,10 \\
\hline \hline
\end{tabular}

Tabela 4 - Estação de jusante - $E_{(J)}$

\begin{tabular}{c|c|c|c|c}
\hline \hline \multirow{2}{*}{ Datas } & $\begin{array}{c}\text { Régua } \\
\text { limnimétrica } \\
(\mathrm{m})\end{array}$ & Vazão $\left(\mathrm{m}^{3} / \mathrm{s}\right)$ & $\begin{array}{c}\text { Concentração } \\
\text { de sedimentos } \\
(\mathrm{ppm})\end{array}$ & $\begin{array}{c}\text { Descarga } \\
\text { sólida total } \\
(\text { ton/dia })\end{array}$ \\
\hline \hline
\end{tabular}




\begin{tabular}{c|c|c|c|c}
\hline \hline 03/jul/2004 & 5,40 & 170,80 & 0,80 & 122,30 \\
\hline 16/out/2004 & 5,42 & 173,04 & 0,20 & 60,90 \\
\hline 25/jan/2005 & 5,65 & 236,55 & 0,60 & 170,62 \\
\hline 22/abr/2005 & 5,64 & 232,35 & 2,80 & 331,27 \\
\hline 22/jul/2005 & $6,40^{*}$ & 161,37 & 0,80 & 41,86 \\
\hline 03/out/2005 & $6,39^{*}$ & 153,14 & 0,20 & 17,73 \\
\hline \hline
\end{tabular}

(*) Relocada a estação fluviométrica de jusante para as proximidades da casa de força da $\mathrm{PCH}$ devido a inadequação do local para instalação do medidor digital de nível fluviométrico.

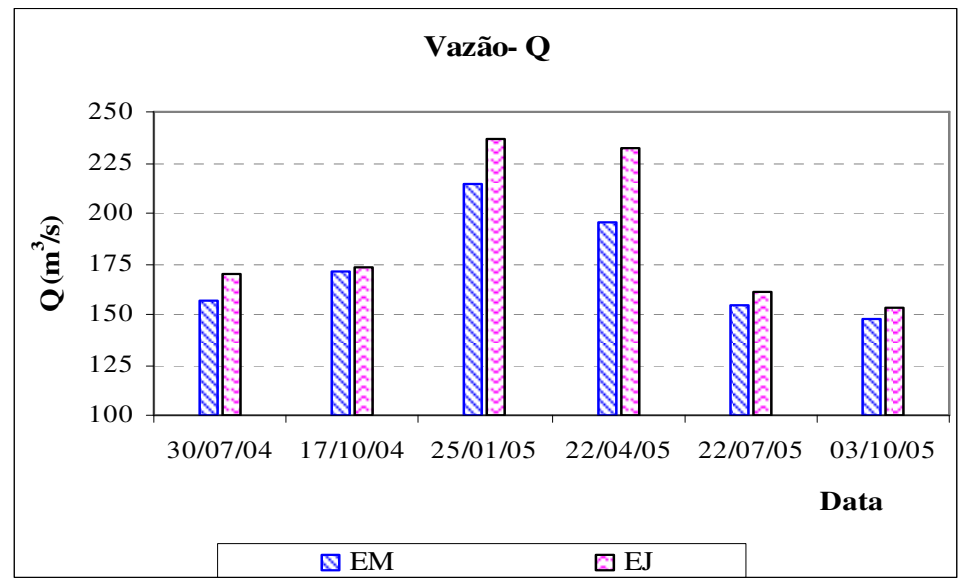

Figura 22 - Valores de Vazão nas estações $E_{(M)}$ e $E_{(J)}$

Os valores das Vazões estão apresentados na figura 22. As descargas sólidas em suspensão (medida) e das descargas sólida total estão apresentadas na tabela 5 e pela figura 25 .

Tabela 5 - Valores de Vazão, Descarga Sólida Medida e Descarga Sólida Total.

\begin{tabular}{c|c|c|c|c}
\hline \hline Data & $\begin{array}{c}\text { Variável } \\
\text { Estação }\end{array}$ & $\begin{array}{c}\text { Vazão } \\
\left(\mathrm{m}^{3} / \mathrm{seg}\right)\end{array}$ & $\begin{array}{c}\text { Descarga Sólida } \\
\text { Medida } \\
\text { (ton/dia) }\end{array}$ & $\begin{array}{c}\text { Descarga } \\
\text { Sólida Total } \\
\text { (ton/dia) }\end{array}$ \\
\hline \hline \multirow{2}{*}{ 03/jul/2004 } & $\mathrm{E}_{(\mathrm{M})}$ & 156,15 & 13,49 & 61,96 \\
\cline { 2 - 5 } & $\mathrm{E}_{(\mathrm{J})}$ & 170,00 & 11,81 & 122,30 \\
\hline \hline \multirow{2}{*}{ 16/out/2004 } & $\mathrm{E}_{(\mathrm{M})}$ & 171,20 & 5,92 & 42,41 \\
& $\mathrm{E}_{(\mathrm{J})}$ & 173,04 & 2,99 & 60,90 \\
\hline \hline
\end{tabular}




\begin{tabular}{c|c|c|c|c}
\hline \multirow{2}{*}{$25 / j a n / 2005$} & $\mathrm{E}_{(M)}$ & 214,16 & 7,40 & 61,48 \\
\cline { 2 - 5 } & $\mathrm{E}_{(\mathrm{J})}$ & 236,55 & 12,26 & 170,62 \\
\hline \hline \multirow{2}{*}{$22 / a b r / 2005$} & $\mathrm{E}_{(M)}$ & 195,137 & 20,23 & 98,50 \\
& $\mathrm{E}_{(\mathrm{J})}$ & 232,358 & 52,34 & 331,27 \\
\hline \hline \multirow{2}{*}{$22 / j u l / 2005$} & $\mathrm{E}_{(M)}$ & 154,518 & 2,67 & 23,20 \\
\cline { 2 - 5 } & $\mathrm{E}_{(\mathrm{J})}$ & 161,368 & 11,15 & 41,86 \\
\hline \hline \multirow{2}{*}{$03 /$ out/2005 } & $\mathrm{E}_{(\mathrm{M})}$ & 147,441 & 30,57 & 86,10 \\
\cline { 2 - 5 } & $\mathrm{E}_{(\mathrm{J})}$ & 153,057 & 2,65 & 17,73 \\
\hline \hline
\end{tabular}

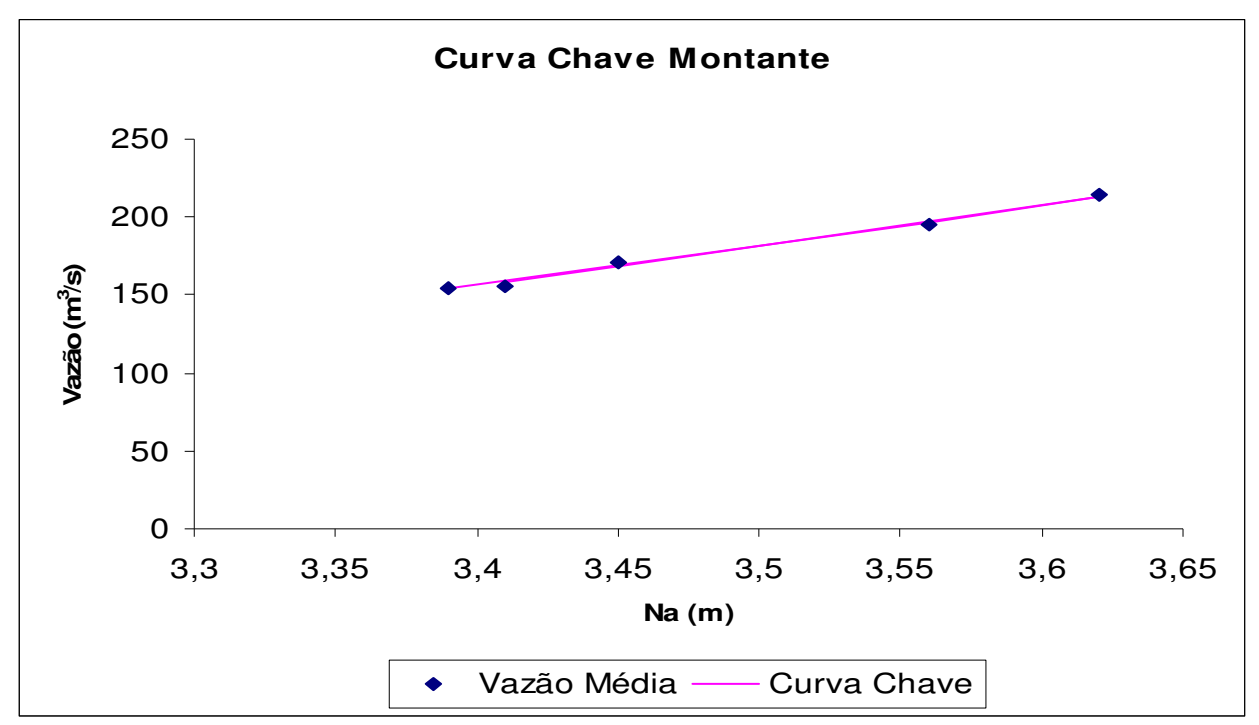

Figura 23 - Curva Chave da Estação de Montante $\mathrm{E}_{(\mathrm{M})}$.

$\mathrm{Na}$ figura 23 foram desconsiderados os valores de Vazão da sexta campanha por não se ajustarem à curva o que leva a acreditar que pode ter ocorrido um erro na medição.

A Curva Chave à montante da $\mathrm{PCH}$ é representada pela equação:

$$
\mathrm{Q}=0,354531 \times \mathrm{H}^{4,975813}
$$

Onde:

$$
\begin{aligned}
& \mathrm{Q}=\text { Vazão em } \mathrm{m}^{3} / \mathrm{s} \\
& \mathrm{H}=\mathrm{Na} \text { (nível da água) em metros }
\end{aligned}
$$




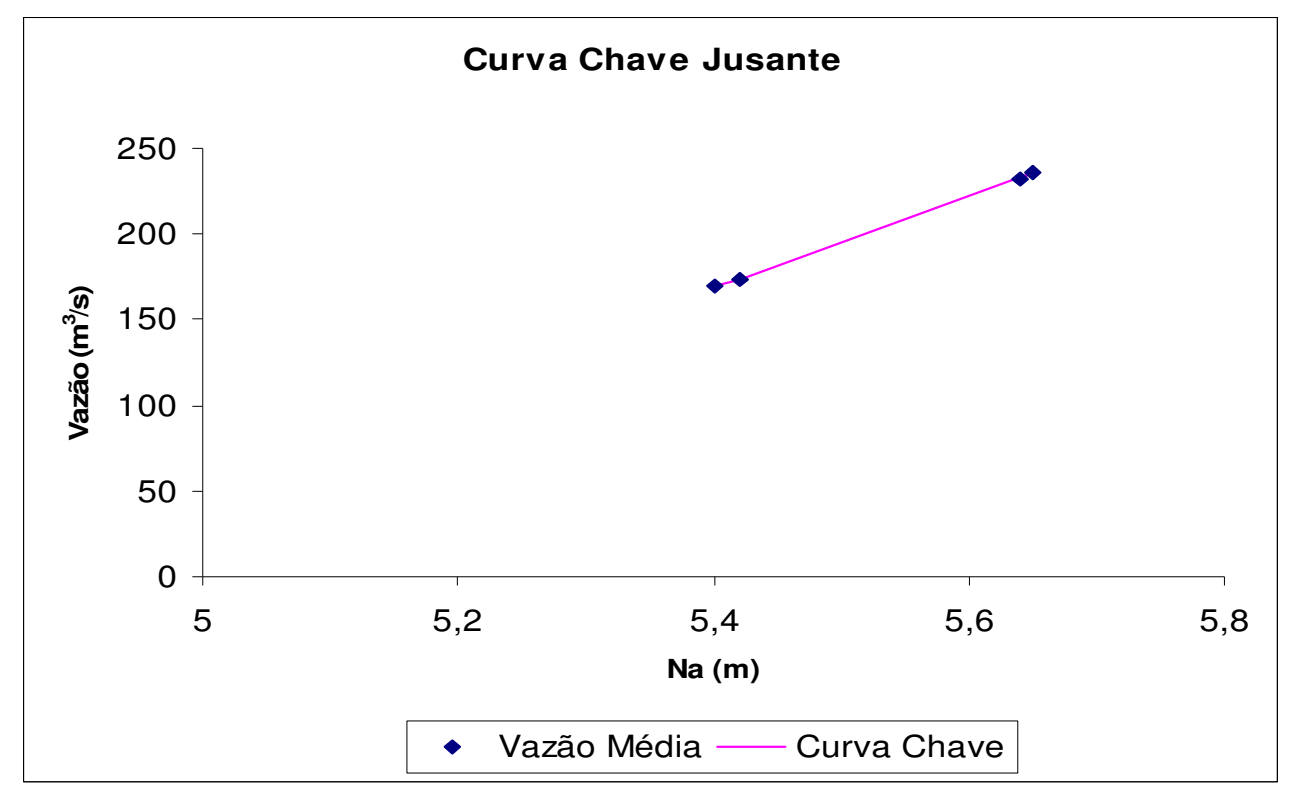

Figura 24 - Curva Chave da Estação de Jusante $\mathrm{E}_{(\mathrm{J})}$.

$\mathrm{Na}$ figura 24 foram desconsiderados os valores de Vazão da quinta e sexta campanha, por não serem valores medidos na mesma seção transversal, portanto não se ajustando a curva.

A Curva Chave à jusante da $\mathrm{PCH}$ é representada pela equação:

$$
\mathrm{Q}=0,000766 \times \mathrm{H}^{7,29764}
$$

Onde:

$$
\begin{aligned}
& \mathrm{Q}=\text { Vazão em } \mathrm{m}^{3} / \mathrm{s} \\
& \mathrm{H}=\mathrm{Na} \text { (nível da água) em metros }
\end{aligned}
$$

É necessário ressaltar que as curvas chaves elaboradas no presente trabalho foram elaboradas a partir de seis campanhas, portanto possuindo seis valores de Vazão medidos, abordando apenas caráter ilustrativo, pois segundo a ANEEL são necessários no mínimo doze valores de Vazão para que haja representatividade. 


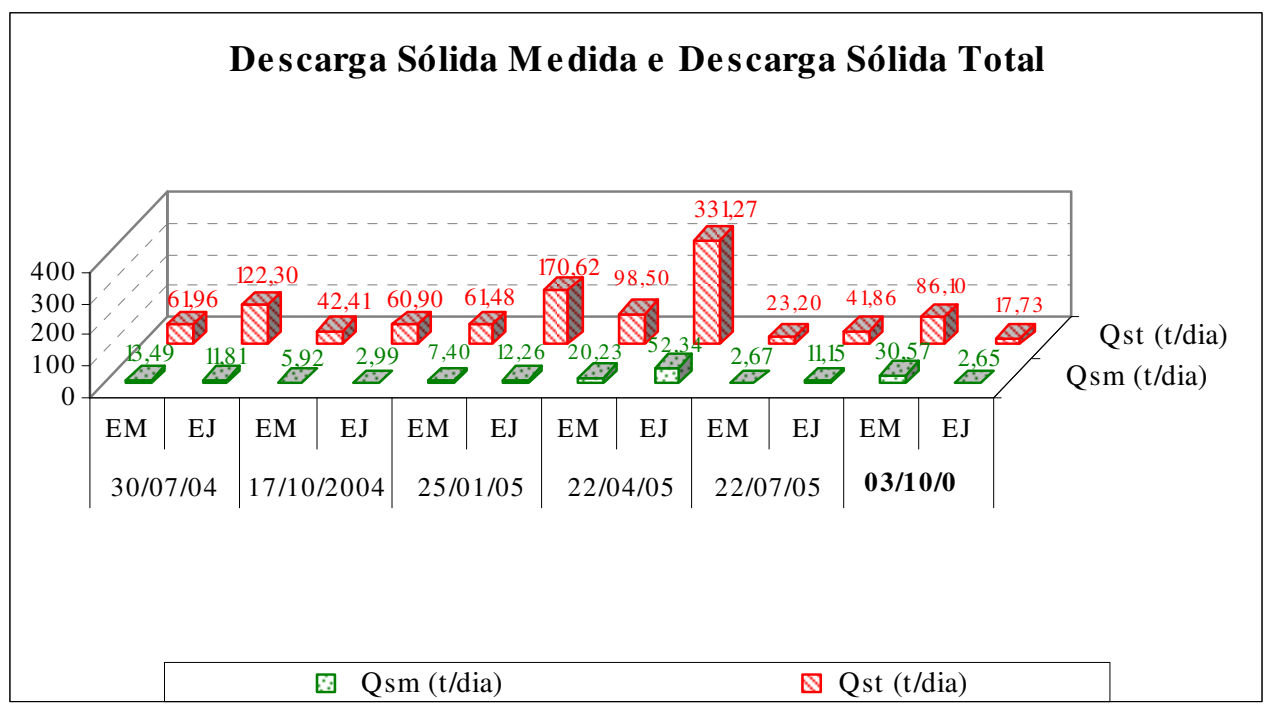

Figura 25 - Relação entre a Descarga Sólida Medida e Descarga Sólida Total nas estações $E_{(M)}$ e $E_{(J)}$.

A Figura 25 mostra que ocorreu aumento aparente no transporte de sedimentos na estação de jusante em relação a montante na campanha de abril/2005 e posteriormente decréscimo nas campanhas seguintes, o diagnóstico destes resultados leva a crer que tais alterações se devem as ações antrópicas, a montante da $\mathrm{PCH}$, e provavelmente tal elevação desses valores se deve ao período de maior intensidade de escavação no entorno do empreendimento.

Tabela 6 - Valores de Descarga Sólida Total e Produção de Sedimentos nas estações a montante e a jusante do empreendimento.

\begin{tabular}{c|c|c|c}
\hline Data & $\begin{array}{c}\text { Variável } \\
\text { Estação }\end{array}$ & $\begin{array}{c}\text { Descarga } \\
\text { Sólida Total } \\
\text { (ton/dia) }\end{array}$ & $\begin{array}{c}\text { Produção de } \\
\text { Sedimentos } \\
\text { (ton/km².ano) }\end{array}$ \\
\hline \multirow{2}{*}{ 03/jul/2004 } & $\mathrm{E}_{(\mathrm{M})}$ & 61,96 & 3,54 \\
\cline { 2 - 4 } & $\mathrm{E}_{(\mathrm{J})}$ & 122,30 & 6,74 \\
\hline \multirow{2}{*}{ 16/out/2004 } & $\mathrm{E}_{(\mathrm{M})}$ & 42,41 & 2,42 \\
\cline { 2 - 4 } & $\mathrm{E}_{(\mathrm{J})}$ & 60,90 & 3,36 \\
\hline \hline \multirow{2}{*}{ 25/jan/2005 } & $\mathrm{E}_{(\mathrm{M})}$ & 61,48 & 3,51 \\
\cline { 2 - 4 } & $\mathrm{E}_{(\mathrm{J})}$ & 170,62 & 9,42 \\
\hline \hline
\end{tabular}




\begin{tabular}{c|c|c|c}
\hline \hline \multirow{2}{*}{ 22/abr/2005 } & $\mathrm{E}_{(\mathrm{M})}$ & 98,50 & 5,62 \\
\cline { 2 - 4 } & $\mathrm{E}_{(\mathrm{J})}$ & 331,27 & 18,29 \\
\hline \hline \multirow{2}{*}{ 22/jul/2005 } & $\mathrm{E}_{(\mathrm{M})}$ & 23,20 & 1,32 \\
\cline { 2 - 4 } & $\mathrm{E}_{(\mathrm{J})}$ & 41,86 & 2,31 \\
\hline \hline \multirow{2}{*}{ 03/out/2005 } & $\mathrm{E}_{(\mathrm{M})}$ & 86,10 & 5,35 \\
\cline { 2 - 4 } & $\mathrm{E}_{(\mathrm{J})}$ & 17,73 & 0,97 \\
\hline \hline
\end{tabular}

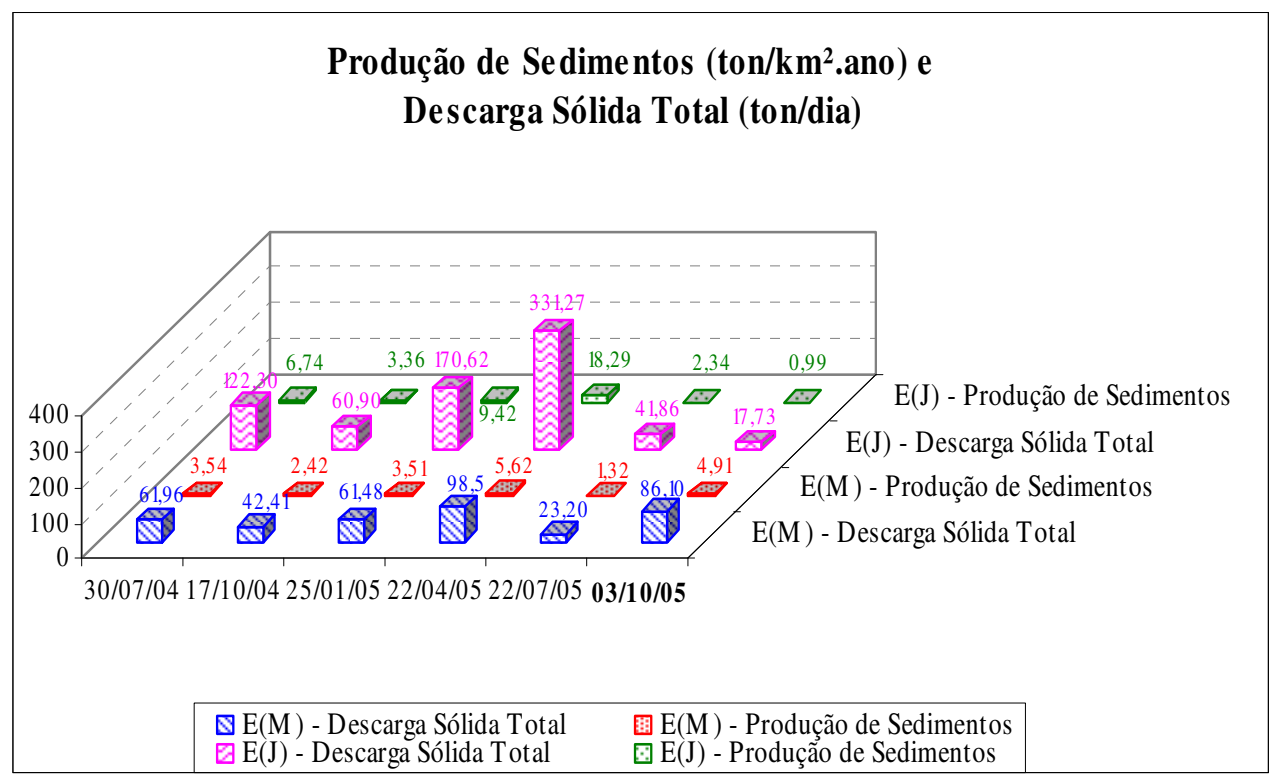

Figura 26 - Relação entre a Descarga Sólida Total e Produção de Sedimentos nas estações $E_{(M)}$ e $E_{(J)}$.

A tabela 6 e a figura 26 apresentam as variações de produção de sedimentos e de descarga sólida total, obtidas a montante e jusante da $\mathrm{PCH}$.

Quanto ao enquadramento a bibliografia "Guia de avaliação de assoreamento de reservatórios", avaliando os resultados pela tabela 7 , a sua classificação se mantém como de baixo produtor de sedimentos, observando na figura 26 que 0 maior valor encontrado foi $18,29 \mathrm{ton} / \mathrm{km}^{2}$. ano na estação de jusante a $\mathrm{PCH}$, estando bem abaixo do limite de 35 ton $/ \mathrm{km}^{2}$.ano.

Tabela 7 - Valores de produção de sedimentos aceitáveis.

\begin{tabular}{c|c}
\hline \hline Tolerância & Produção de Sedimentos \\
\hline
\end{tabular}




\begin{tabular}{|c|c|c|}
\hline & (ton/mi².ano) & (ton $/ \mathrm{km}^{2}$.ano) \\
\hline Alta & $>500$ & 175 \\
\hline Moderada & 200 a 500 & 70 a 175 \\
\hline Baixa & $<100$ & 35 \\
\hline
\end{tabular}

Fonte: Guia de avaliação de assoreamento de reservatórios - ANEEL.

\section{Análise granulométrica dos sedimentos do leito do rio Sacre}

A análise granulométrica foi feita pelo método do peneiramento, em que se utiliza uma série de peneiras-padrão agitadas mecanicamente e por tempo determinado em aparelhos denominados "ro-tap".

O material coletado foi do leito no talvegue da seção de medição fluviométrica de montante e de jusante.

Os materiais amostrados foram enquadrados pela classificação granulométrica da American Geophysical Union, que é recomendado internacionalmente (CARVALHO, 1994).

A composição percentual dos materiais dos leitos a montante e jusante da $\mathrm{PCH}$ está apresentada na tabela 8.

Tabela 8 - Valores percentuais do material do leito nas seções de medições fluviométricas nas estações a montante e a jusante

\begin{tabular}{c|c|c|c}
\hline $\begin{array}{c}\text { Diâmetros } \\
(\mathrm{mm})\end{array}$ & Denominação & $\mathrm{E}_{(\mathrm{M})}(\%)$ & $\mathrm{E}_{(\mathrm{J})}(\%)$ \\
\hline \hline 0,125 a 0,25 & Areia fina & 12,6 & 5,5 \\
\hline 0,25 a 0,50 & Areia média & 45,2 & 29,5 \\
\hline 0,50 a 1,0 & Areia grossa & 37,4 & 45,3 \\
\hline 1,0 a 2,0 & $\begin{array}{c}\text { Areia muito } \\
\text { grossa }\end{array}$ & 4,8 & 19,7 \\
\hline
\end{tabular}

Os resultados apresentam alterações na amostragem de jusante, em que se teve aumento na granulometria. Esta alteração pode ser o carreamento de material de movimento de terra da obra, que não se apresenta em suspensão e sim no fundo do leito. 


\section{CONCLUSÕES}

O estudo hidrossedimentológico e da qualidade da água, em etapa de construção desta obra hidráulica, através da realização de seis campanhas seguidas de análises e comparações dos resultados obtidos, viabiliza a apresentação do seguinte diagnóstico:

Para as variáveis físico-químicas analisadas constatou-se que dentro do enquadramento da Resolução CONAMA n. 357/2005 mantém-se sem nenhuma objeção ou interferência para enquadramento na Classe 2.

Os índices de coliformes obtidos nos pontos de amostragem nesta campanha foram baixos e inferiores aos estabelecidos pela Resolução CONAMA n. 357/2005 para rios de Classe 2, o que pode indicar ótimo aspecto sanitário da água do rio Sacre.

Quanto à avaliação hidrossedimentológica constata-se com os resultados deste estudo, que não se nota preocupação com o transporte de sedimentos relativo a assoreamento no entorno do empreendimento e pode se dizer que os valores obtidos são insignificantes.

Quanto à qualidade de água, os resultados das variáveis físicos e organolépticas registraram-se valores típicos, mantém-se a transparência total, em algumas campanhas o pH teve um valor abaixo do limite da resolução $\mathrm{n}^{\circ}$. 357/2005 do CONAMA. Com a baixa vazão em solo ácido de cerrado implicou em baixos valores para $\mathrm{pH}$. Interferência sem justificativa no acréscimo dos resultados na cor e baixos valores para a turbidez, mas a água continua de boa qualidade.

Foi possível constatar que a construção mantém-se com pouca interferência ao meio ambiente no que diz respeito à Qualidade da Água e na avaliação Hidrossedimentológica.

Observou-se que tal empreendimento produz pouca alteração ao curso d'água, por se tratar de um aproveitamento hidráulico que dispensa o barramento, tendo em vista que para o desenvolvimento é necessário que haja certos custos a natureza, sendo assim que seja possível optar pelo menor deles.

É relevante a necessidade da continuação de tais estudos na fase de operação 
da PCH Sacre 2.

\section{BIBLIOGRAFIA}

ALLAN, J. D. Stream Ecology - Structure and function of running waters. London. Chapman \& Hall, 388 p., 1995.

CARVAlHO, N. O. Hidrossedimentologia Prática, ed. CPRM. Rio de Janeiro/RJ. 1994.

CONAMA - Conselho Nacional do Meio Ambiente. Resolução no 357, de 17 de março de 2005. Ministério do Meio Ambiente, 23p. 2005.

ESTEVES, F.A. Fundamentos de Limnologia. Rio de Janeiro: Editora Interciência. 574p. 1988.

Recebido: 10/09/2013

Aprovado: 13/04/2014 